\title{
Evaluation of Claudin-1 and Ki-67 in Different Molecular Subtypes of Breast Ductal Carcinoma: Immunohistochemical Study
}

\author{
MARWA S. ABD ALLAH, M.D.*; AMR F. EL-SEBAAIE, M.D.**; EMAN S. OMAR, M.D.*; \\ EMAN A. SAAD, M.Sc.* and SAMIA A. YOUSSEF, M.D.* \\ The Departments of Pathology, Faculty of Medicine, Benha University* and Military Medical Academy**, Cairo, Egypt
}

\begin{abstract}
Background: The role of claudin-1 in aggressiveness and increased metastatic phenotype is controversial issue in different cancers.

Aim of Study: Evaluation of immunohistochemical expression of Claudin-1 and Ki-67 in different molecular subtypes of breast ductal carcinoma and correlation with other prognostic clinicopathologic factors.
\end{abstract}

Patients and Methods: This is a retrospective controlled Immunohistochemical study performed to examine the expression of Claudin-1 and Ki-67 in 54 cases of breast ductal carcinoma (NST) with different molecular subtypes. Statistical analysis methods were used to evaluate the relationship between Claudin-1 and Ki-67 with various clinicopathological, parameters and molecular subtypes.

Results: 19 cases (35.2\%) were Luminal A, 14 cases (25.9\%) were Luminal B, 10 cases $(18.5 \%)$ were Her2 Enriched, and 11 cases $(20.4 \%)$ were Triple Negative (TN). There is a statistically significant correlation between claudin$1 \& \mathrm{Ki}-67$ expression and various pathological parameters and molecular subtypes. High expression of both markers have direct significant correlation with poor prognostic factors as higher tumor grade and, higher nuclear grade, large tumor size, positive lymph node metastasis, positive distant metastasis, high stage, positive LVI and poor NPI. Luminal B and TN tumors have higher Ki-67 compared to other subtypes. TN tumors \& Her2 enriched tumors have higher claudin-1 expression compared to other subtypes. All luminal A tumors have low expression of both Ki-67 and caludin1.

Conclusions: Claudin-1 overexpression is associated with poor prognostic factors and high $\mathrm{Ki}-67$ proliferative index in breast ductal carcinoma and may have diagnostic role in discrimination between different molecular subtypes of breast ductal carcinoma.

Key Words: Breast ductal carcinoma - Claudin-1 - Ki-67 Molecular subtypes of breast cancer.

Correspondence to: Dr. Marwa Said Abd Allah, The Department of Pathology, Faculty of Medicine, Benha University, Cairo, Egypt

\section{Introduction}

BREAST cancer is the most common cancer and the second leading cau se of cancer death in women worldwide [1]. In Egypt, Cancer breast is the most common cancer among women, representing 18.9\% of total cancer cases and $37.6 \%$ of female cancers [2].

Breast cancer is a clinically highly heterogeneous disease with distinct pathological and histological features. Breast cancer is classified into different molecular subtypes that are often distinguished by immunohistochemical staining of the Estrogen Receptor (ER), Progesterone Receptor (PR), and HER2, along with Ki-67 staining [3] .

Tight Junctions (TJs) form the closes contacts between adjacent cells along the apical border of the epithelial cell membrane. They are involved in maintaining the architecture and functional integrity of the cell and linked to the machinery that controls apicobasal polarization [4]. Three types of integral membrane proteins constitute the tight junctions; the claudins, occludin and the junctional adhesion molecules [5] . claudin-1 is a transmembrane protein responsible for maintaining cellular polarity and playing major role in cell-cell communication and epithelial cell homeostasis [6]

The interruption of $\mathrm{TJ}$ during tumorigenesis leads to invasiveness, loss of cohesion and lack of differentiation in tumor cells [7]. Claudin is involved in tumor progression by its important role in migration, invasion and metastasis of tumor cells.

\footnotetext{
Abbreviations:

NST : Invasive Carcinoma of no Special Type.

NPI : Nottingham Prognostic Index.

LVE : Lymphovascular Invasion.

TN : Triple Negative.
} 
Some studies have shown that they play a role in the Epithelial to Mesenchymal Transition (EMT) and in the formation of tumor stem cells or tumorinitiating cells (CSC/TIC), however the actual underlying mechanism remains uncertain [8]

Claudin-1 expression is frequently altered in different types of cancer [9]. In some cancers as lung cancer and hepatocellular carcinoma, loss of claudin- 1 has been linked to cancer progression and invasion, and the acquisition of the metastatic potential. Conversely, in other cancers, such as oral squamous cell carcinoma, gastric carcinoma and melanoma, over expression of claudin- 1 has been associated with aggressiveness and increased metastatic phenotype [6]

$\mathrm{Ki}-67$ is a nuclear protein associated with cell proliferation. Nuclear antigen Ki-67 is expressed in certain phases of the cell cycle namely S, G1, G2 and M phases, but is not present in G0 [10] Therefore, the proliferative activity determined by Ki-67 may reflect the aggressive behavior of breast cancer and predict the recurrence time and appropriate therapy required in treatment [11]

The present study aimed to appreciate the correlation between claudin-1 and Ki-67 proliferative index in breast ductal carcinoma and evaluate their diagnostic role in differentiating between different molecular subtypes in addition to their correlation with the various definite clinical-pathological parameters including Nottingham Prognostic Index (NPI).

\section{Patients and Methods}

This is a retrospective study on 54 cases of female breast ductal carcinoma, (Invasive Carcinoma of No Special Type NST). Ten cases of benign breast lesions were taken as control. Archived formalin-fixed, paraffin embedded blocks of tumor specimens, were collected from Benha Pathology Department, Faculty of Medicine, Benha University and International Medical Center in the period from the years (2013-2016). The clinicopathological data concerning age of patients, tumor size, hormonal status and distant metastasis were collected from the files of patients after approval by the Ethical Committee at Faculty of Medicine, Benha University.

Histopathological study: Four-micron thick sections were stained by conventional hematoxylin and eosin (H \& E) stain. Two blind expert pathologists independently confirmed histologic diagnosis of each lesion and grading.
Immunohistochemical study: For Immunohistochemical (IHC) staining, 10\% formalin-fixed, paraffin-embedded, 4-micron tissue sections on positive slides were prepared. Immunostaining was applied for ER mouse monoclonal (1D5 ) antibody (Thermo Fisher scientific anatomical pathology, USA) prediluted ready to use, PR mouse monoclonal (Alpha PR6) antibody (Thermo Fisher scientific anatomical pathology, USA) prediluted ready to use, HER2 mouse monoclonal (3B5) antibody (Thermo Fisher scientific anatomical pathology, USA) prediluted ready to use, Ki-67 Rabbit polyclonal antibody (Thermo Fisher scientific anatomical pathology, USA) prediluted ready to use and claudin-1, Rabbit polyclonal antibody (Thermo Fisher scientific anatomical pathology, USA) prediluted ready to use. DAP was utilized as a chromogen. IHC staining was performed using Detection kit (Fremont, USA) according to the manufacturer's guidelines. Endocervical epithelium, endometrial tissue, gastric carcinoma, lymphoid tissue of tonsil and normal skin were used as positive control for ER, PR, HER2, Ki-67 and claudin-1, respectivelly. Negative control for all was achieved by omitting the primary antibody.

\section{Interpretation of immunohistochemical staining:}

$E R$ : The expression was detected as nuclear staining. Percentages of ER expression were estimated from the entire tumor area. Nuclear Staining in $>10 \%$ of tumor cells was considered positive.

$P R$ : The expression was detected as nuclear staining. Percentages of PR expression were estimated from the entire tumor area. Nuclear Staining in $>10 \%$ of tumor cells was considered positive.

HER2: Strong, circumferential membranous staining in $>30 \%$ of invasive carcinoma cells was scored as 3+; moderate, circumferential membranous staining in $\geq 10 \%$ of invasive tumor cells or $3+$ staining in $<30 \%$ of cells was scored as $2+$; weak and incomplete membranous staining in invasive tumor cells was scored as $1+$; and no staining was scored as 0 . Tumors with 0 and $1+$ staining were considered negative, cases scored as $2+$ were considered equivocal, and cases with $3+$ staining were considered positive.

Ki-67: The expression was detected as dot like brown nuclear staining. Percentages of Ki-67 expression were estimated from the entire tumor area. By using Roc curve, the optimal cut-off point for the Ki-67 index was $14 \%$. Low Ki-67 value $(<14 \%)$ and High Ki-67 value (> $14 \%$ ) similar to work done by Wang et al., [12]. 
Claudin-1: The expression was detected as membranous and diffuses cytoplasmic staining. Immunoreactivity was assessed based on a combined score of extent and intensity of staining. Scores 0-3 were assigned according to the percentage of positive tumor cells $(0=0 \% ; 1=<25 \% ; 2=25$ $50 \% ; 3=>51 \%)$ and the intensity of staining in tumor $(0=0 ; 1=1+; 2=2+; 3=3+)$. The two scores were multiplied to give an overall score of $0-9$, of which 0 was considered negative, 1-2 weak, 3-6 moderate, and 9 strong staining. Negative and weak expression was considered as low, whereas moderate and strong as high [9]. By using Roc curve, the optimal cut-off point for the claudin-1 index was 2 . Lower claudin-1 value was $(<2) \&$ higher claudin-1 value was (>2).

\section{Statistical analysis:}

All statistical analyses were carried out using Statistical Package for the Social Science (SPSS) program, Version 16, on a personal computer. The Pearson correlation coefficient, chi square tests \& Fisher exact test were used. $p$-value $<0.05$ was considered significant $\& p$-value $<0.01$ was considered highly significant. Receiver Operator Characteristic (ROC) curve was also used to determine the cut off value of Ki-67 and claudin- 1 and their diagnostic performances to discriminate the molecular subtypes of breast ductal carcinoma.

\section{Results}

The present retrospective study enrolled 54 cases of female breast ductal carcinoma (NST). Ten cases of apparently normal breast tissue were taken as control. The age of patient with breast (NST) ranged from 29 to 72 years old, median age 50 years old. 6 cases $(11.1 \%)$ were grade I, 29 cases $(53.7 \%)$ were grade II and 19 cases $(35.2 \%)$ were grade III. Regarding TNM staging 18 cases $(33.3 \%)$ were stage (I), 18 cases $(33.3 \%)$ were stage II, 9 cases $(16.7 \%)$ were Stage III and 9 cases $(16.7 \%)$ were stage IV.

\section{Nottingham prognostic index (NPI) results:}

NPI showed a statistically significant correlation with all of age $(p<0.05)$, tumor grade $(p<0.01)$, nuclear grade $(p<0.01)$, tumor size $(p$-value $<0.01)$, lymph node metastasis $(p<0.01)$, distant metastasis $(p<0.05)$, stage $(p<0.01)$ and lymphovascular invasion $(p<0.01)$.

\section{Ki-67 immunohistochemical staining results:}

All ten control cases showed low nuclear expression of Ki-67. Out of the 54 cases of IDC, 37 cases $(68.5 \%)$ showed high nuclear expression and
17 cases (31.5\%) showed low nuclear expression of $\mathrm{Ki}-67$.

High Ki-67 index showed statistically significant correlation with high tumor grade $(p<0.01)$, nuclear grade $(p<0.01)$, tumor size $(p=0.05), \mathrm{LN}$ metastasis $(p<0.01)$, lymphovascular invasion $(p<0.01)$, distant metastasis $(p<0.05)$, tumor stage $(p<0.01)$ and NPI $(p$-value $<0.01)$.

High Ki-67 index showed inverse correlation with ER/PR status and positive correlation with Her2 status $(p<0.01)$ and molecular subtypes $(p<0.01)$. The Correlation between Ki-67 index and different pathologic variables and molecular subtypes of study cases was detailed in (Table 1).

\section{Molecular subtypes results:}

Molecular classification involved 19 cases (35.2\%) of Luminal A type, 14 cases $(25.9 \%)$ of Luminal B type, 10 cases (18.5\%) of Her2 enriched type and 11 cases $(20.4 \%)$ of triple negative type.

A significant statistical correlation between molecular subtypes of cases and age $(p<0.01)$ was found as $80 \%$ \& $79 \%$ of luminal A \& B tumors respectively were detected in age more than 50 years old while $70 \%$ \& $73 \%$ of Her 2 enriched and $\mathrm{TN}$ cases occurred with young age ( $<50$ years old).

A positive significant statistical correlation was detected between molecular subtypes and tumor grade $(p<0.01)$, nuclear grade $(p<0.01)$, tumor size $(p<0.01)$, lymphovascular invasion $(p<0.01)$, lymph node metastasis $(p<0.01)$, distant metastasis $(p<$ $0.05)$, stage $(p<0.01)$ and NPI $(p<0.01)$.

\section{Claudin-1 immunohistochemical staining results:}

All ten control cases showed predominantly apicolateral claudin-1 membranous staining pattern of ductal epithelial cells. Out of 54 cases of invasive carcinoma NST (IDC), 26 cases (48\%) showed high expression of cluadin1 (membranous \& $\mathrm{Cy}-$ toplasmic staining pattern) and 28 cases (52\%) showed low expression of cluadin-1.

High claudin-1 expresion showed a statistically significant correlation with all of tumor grade $(p$ $<0.01)$, nuclear grade $(p<0.01)$, tumor size $(p<0.01)$, lymphovascular invasion $(p<0.01)$, lymph node metastasis $(p<0.01)$, distant metastasis $(p<0.01)$, stage $(p<0.01) \&$ NPI $(p<0.01)$.

High claudin-1 expression showed inverse correlation with ER/PR status $(p<0.01)$ and positive correlation with molecular subtypes $(p<0.01)$. The Correlation between claudin- 1 and different path- 
ologic variables and molecular subtypes of study cases was detailed in (Table 1).

\section{ROC curve results:}

The receiver operating characteristics curve analysis showed that the diagnostic performance of both Ki-67 and claudin-1 in discriminating molecular subtypes of breast cancer was accepted. claudin-1 is most sensitive while $\mathrm{Ki}-67$ is most specific in diagnosis of molecular subtypes of invasive carcinoma NST as shown in (Table 3 ) and Fig. (1).

Table (1): Correlation between Ki-67 and Claudin1 expression with pathological and molecular variables.

\begin{tabular}{|c|c|c|c|c|c|c|c|}
\hline \multirow{2}{*}{$\begin{array}{l}\text { Clinicoimmuno } \\
\text { pathological variables }\end{array}$} & \multirow{2}{*}{ Total } & \multicolumn{2}{|c|}{$\begin{array}{c}\text { Ki-67 expression } \\
\text { High }\end{array}$} & \multirow[t]{2}{*}{$p$-value } & \multicolumn{2}{|c|}{$\begin{array}{l}\text { Claudin-1 } \\
\text { High }\end{array}$} & \multirow[t]{2}{*}{$p$-value } \\
\hline & & Frequency & $\%$ & & Frequency & $\%$ & \\
\hline \multicolumn{8}{|l|}{ Grade: } \\
\hline I & $6 \quad(11.1 \%)$ & 0 & 0 & 0.000 & 0 & 0 & 0.004 \\
\hline II & $29(53.7 \%)$ & 18 & 62 & HS & 13 & 44.8 & HS \\
\hline III & $19(35.2 \%)$ & 19 & 100 & & 13 & 68.4 & \\
\hline \multicolumn{8}{|l|}{ Nuclear grade: } \\
\hline I & $17(31.5 \%)$ & 5 & 29.5 & 0.000 & 3 & 17.5 & 0.002 \\
\hline II & $17(31.5 \%)$ & 12 & 70.5 & HS & 8 & 47 & HS \\
\hline III & $20(37 \%)$ & 20 & 100 & & 15 & 75 & \\
\hline \multicolumn{8}{|l|}{ Size: } \\
\hline TI & $22(40.7 \%)$ & 12 & 54.5 & 0.050 & 4 & 18 & 0.001 \\
\hline $\mathrm{T} 2$ & $25(46.3 \%$ & 19 & 76 & $\mathrm{~S}$ & 17 & 68 & HS \\
\hline $\mathrm{T} 3$ & $7 \quad(13 \%)$ & 6 & 85.7 & & 5 & 71.5 & \\
\hline \multicolumn{8}{|l|}{ Nodal metastasis: } \\
\hline N0 & $27(50 \%)$ & 13 & 48 & 0.000 & 6 & 22.2 & 0.000 \\
\hline N1 & $12(22.2 \%)$ & 9 & 75 & HS & 7 & 58.3 & HS \\
\hline N2 & $9 \quad(16.7 \%)$ & 9 & 100 & & 7 & 77.8 & \\
\hline N3 & $6 \quad(11.1 \%)$ & 6 & 100 & & 6 & 100 & \\
\hline \multicolumn{8}{|l|}{ Distant metastasis: } \\
\hline M1 & $9 \quad(16.7 \%)$ & 9 & 100 & 0.023 & 8 & 88.9 & 0.009 \\
\hline M0 & $45(83.3 \%)$ & 28 & 63 & $\mathrm{~S}$ & 18 & 40 & HS \\
\hline \multicolumn{8}{|l|}{ Stage: } \\
\hline I & $18(33.3 \%)$ & 9 & 50 & 0.001 & 4 & 22.2 & 0.000 \\
\hline II & $18(33.3 \%)$ & 10 & 55.6 & HS & 6 & 33.3 & HS \\
\hline III & $9 \quad(16.7 \%)$ & 9 & 100 & & 8 & 88.9 & \\
\hline IV & $9 \quad(16.7 \%)$ & 9 & 100 & & 8 & 88.9 & \\
\hline \multicolumn{8}{|c|}{ Lympho-vascular invasion: } \\
\hline Present & $25(46.3 \%)$ & 24 & 96 & 0.000 & 20 & 80 & 0.000 \\
\hline Absent & $29(53.7 \%)$ & 13 & 45 & HS & 8 & 21 & HS \\
\hline Absent & $45(83.3 \%)$ & 28 & 64.5 & & 19 & 42.2 & \\
\hline \multicolumn{8}{|l|}{ NPI: } \\
\hline Excellent & $3(5.6 \%)$ & 0 & 0 & 0.000 & 0 & 0 & 0.000 \\
\hline Good & $15(27.8 \%)$ & 5 & 33.3 & HS & 3 & 20 & HS \\
\hline Moderate I & $10(18.5 \%)$ & 8 & 80 & & 2 & 20 & \\
\hline Moderate II & $7 \quad(13 \%)$ & 5 & 71.5 & & 4 & 57 & \\
\hline Poor & $19(35.2 \%)$ & 19 & 100 & & 17 & 89.5 & \\
\hline \multicolumn{8}{|l|}{ Molecular subtypes: } \\
\hline Luminal A & $15(27.7 \%)$ & 0 & 0 & 0.000 & & & 0.000 \\
\hline Luminal B & $18(33.3 \%)$ & 18 & 100 & HS & 0 & 0 & HS \\
\hline Her2 enriched & $10(18.6 \%)$ & 9 & 90 & & 1 & 10 & \\
\hline Triple negative & $11(20.4 \%)$ & 10 & 91 & & 1 & 9 & \\
\hline
\end{tabular}

HS: Highly Significant. NS: Non Significant. 
Table (2): Correlation between Ki-67 and Claudin-1.

\begin{tabular}{lccc}
\hline & $\mathrm{N}$ & \multicolumn{2}{c}{ Claudin-1 } \\
\cline { 3 - 4 } & & \multicolumn{1}{c}{ Low } & \multicolumn{1}{c}{ High } \\
\hline Ki67 expression: & & & \\
Low & 17 & $17(100 \%)$ & $0(0 \%)$ \\
High & 37 & $11(29.7 \%)$ & $26(70.3 \%)$ \\
\hline Total & 54 & $24(57.1 \%)$ & $18(42.9 \%)$ \\
& & $p<0.001 * *$ & \\
\hline
\end{tabular}

**: Correlation is significant at the 0.01 level (2-tailed).

Table (3): Diagnostic performance for Ki-67 and Claudin-1.

\begin{tabular}{lllccccc}
\hline Molecular type & Marker & AUC & $\begin{array}{c}\text { Sensitivity } \\
(\%)\end{array}$ & $\begin{array}{c}\text { Specificity } \\
(\%)\end{array}$ & $\begin{array}{c}\text { PPV } \\
(\%)\end{array}$ & $\begin{array}{c}\text { NPV } \\
(\%)\end{array}$ & $p$-value \\
\hline Luminal A & Ki67 & 0.792 & 52.63 & 91.43 & 76.92 & 78.05 & $0.000 \mathrm{~S}$ \\
& Claudin-1 & 0.646 & 73.7 & 57.1 & 48.3 & 80.0 & $0.000 \mathrm{~S}$ \\
Luminal B & Ki67 & 0.598 & 85.71 & 57.5 & 36.4 & 90.5 & $0.033 \mathrm{~S}$ \\
& Claudin-1 & 0.766 & 85.7 & 52.5 & 41.4 & 92 & $0.049 \mathrm{~S}$ \\
\multirow{2}{*}{ Her2 enriched } & Ki67 & 0.522 & 70.0 & 63.64 & 21.2 & 85.7 & $0.024 \mathrm{~S}$ \\
& Claudin-1 & 0.731 & 80.0 & 40.9 & 33.3 & 93.3 & $0.012 \mathrm{~S}$ \\
Triple negative & Ki67 & 0.774 & 81.82 & 67.44 & 36.0 & 93.1 & $0.004 \mathrm{~S}$ \\
& Claudin-1 & 0.805 & 90.91 & 62.79 & 41.7 & 96.7 & $0.006 \mathrm{~S}$ \\
\hline
\end{tabular}

AUC : Area Under Curve.

PPV : Positive Predictive Value.

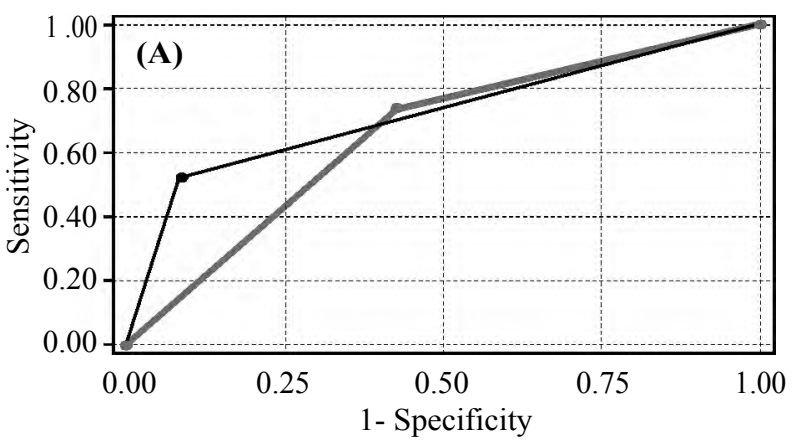

$\rightarrow$ Ki-67 ROC area: 0.972

- Claudin-1 ROC area: 0.646

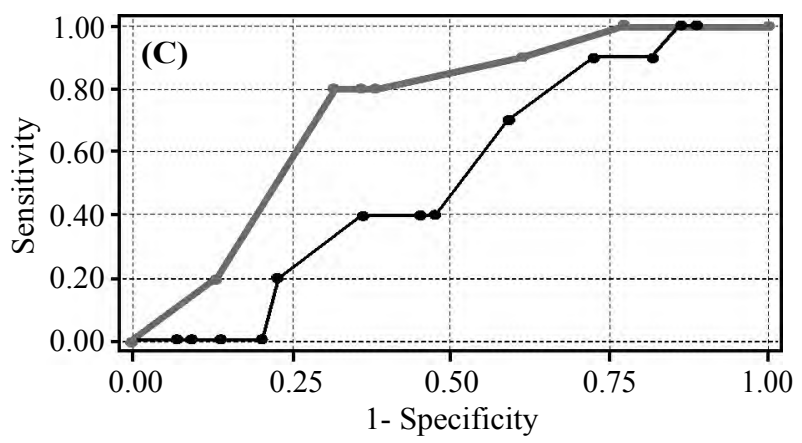

Ki-67 ROC area: 0.5216

Claudin-1 ROC area: 0.7307
NPV: Negative Predictive Value.

S : Significant.
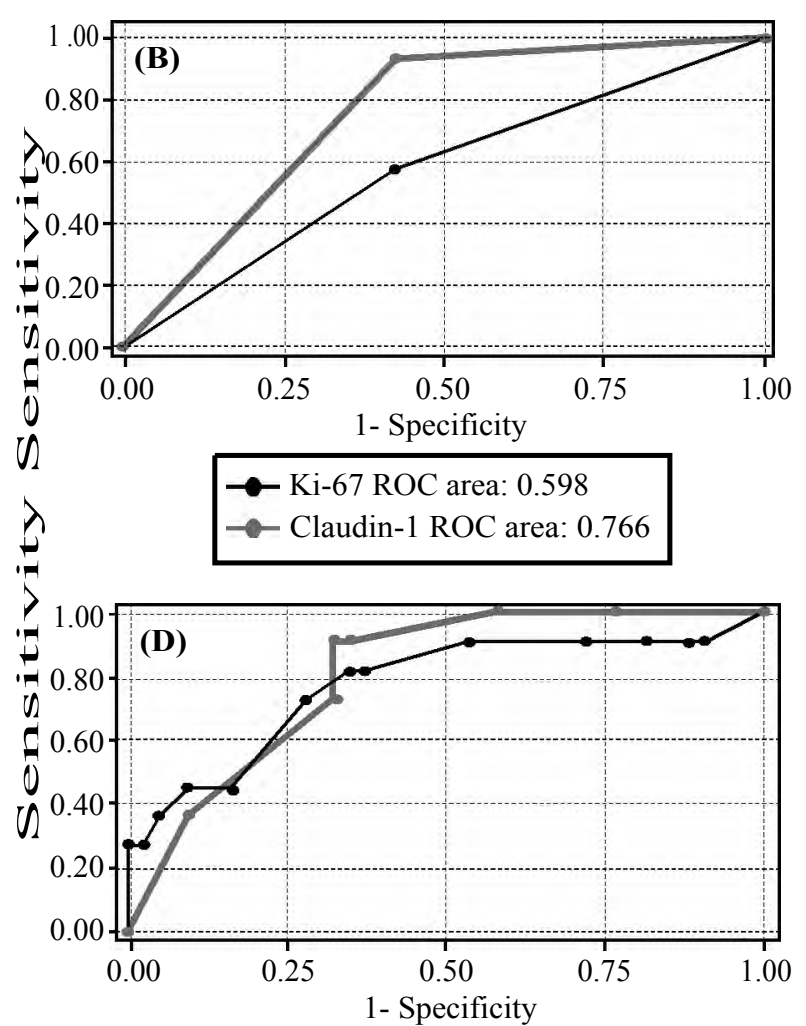

Ki-67 ROC area: 0.7738

Claudin-1 ROC area: 0.8055

Fig. (1): Diagnostic performance of Ki-67 and claudin-1 for Molecular subtypes of breast cancer. (A) Diagnostic performance of Ki-67 and claudin-1 in luminal A. (B) Diagnostic performance of Ki-67 and claudin-1 in luminal B tumors. (C) Diagnostic performance of Ki-67 and claudin-1 in HER2 enriched tumors. (D) Diagnostic performance of Ki-67 and claudin-1 in TN tumors. 


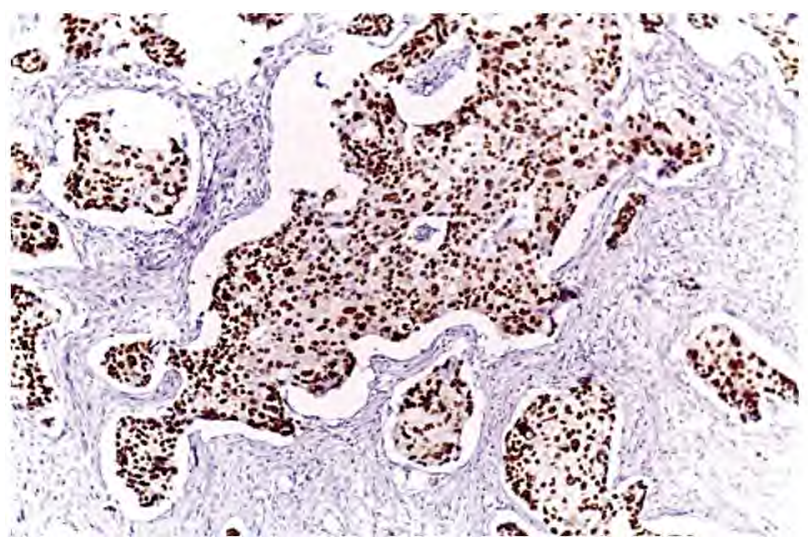

Fig. (2): Invasive ductal carcinoma (NST) showing positive nuclear ER receptor expression (IHC, DAB X100).

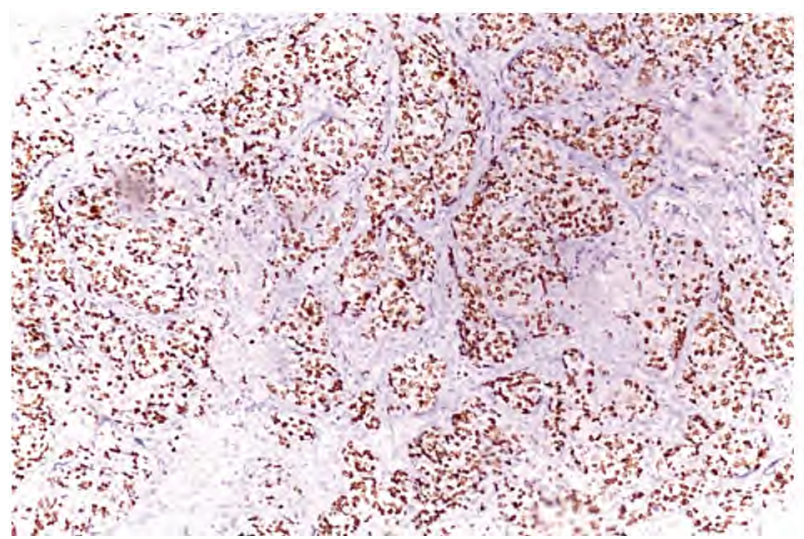

Fig. (4): Invasive ductal carcinoma (NST) showing high nuclear ki67 expression (80\% of tumours area) in case of TNG subtype (IHC, DAB X200).

\section{Discussion}

Invasive breast carcinoma is the most common malignant tumor in women and the second leading cause of cancer death in women worldwide [13] In Egypt, in NCI pathology cancer registry, breast cancer is the foremost oncologic problem, contributing to $20 \%$ of all cancers and $43 \%$ of female cancers [14]

Breast cancer is a clinically highly heterogeneous disease with distinct pathological and histological features. The current histological classifications may not entirely correlate with the clinical behavior of this disease. Molecular subtypes of breast carcinoma in view of ER, PR, Her2neu, EGFR and basal marker expression status can possibly predict and impact the prognosis and response to hormonal and targeted therapies [15]

Nottingham Prognostic Index (NPI) is one of the widely accepted clinical tools used to calculate an individual's prognosis. The current study revealed a statistically significant correlation between

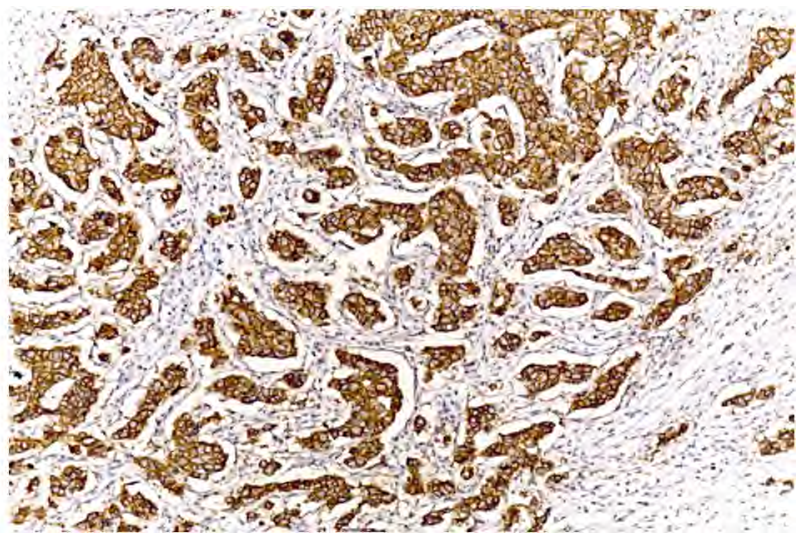

Fig. (3): Invasive ductal carcinoma (NST) showing positive complete strong membranous Her2 expression score 3 (IHC, DAB X400).

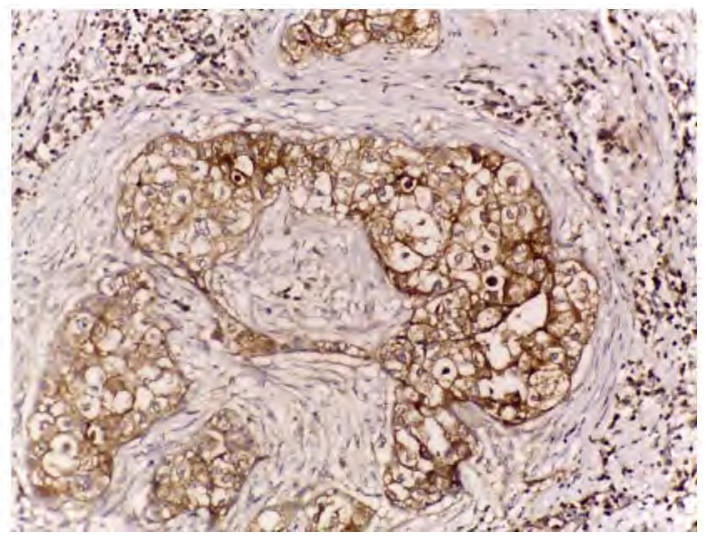

Fig. (5): Invasive ductal carcinoma (NST) showing high claudin 1 cytoplasmic expression score 9 in case of TNG subtype (IHC, DAB X400).

NPI and age $(p<0.05)$, tumor grade $(p<0.01)$, nuclear grade $(p<0.01)$, tumor size $(p<0.01)$, lymph node metastasis $(p<0.01)$, distant metastasis $(p$ value $<0.05)$, stage ( $p$-value $<0.01)$, lymphovascular invasion $(p<0.01)$, and perineural invasion $(p<0.05)$. These results were in parallel yuwith the study of Hearne et al., [16]

The present study revealed a significant statistical correlation between NPI and hormonal receptors $(p<0.05)$. The study also revealed a significant statistical correlation between NPI and Her2 status $\left(p<{ }^{0} .05\right)$.

$\mathrm{Ki}-67$ is an immunohistochemical proliferation marker in many types of cancer and has been widely studied among Breast Cancer patients mostly through retrospective studies [17]. In the present study, high Ki-67 index ( $\geq 14 \%)$ was significantly correlated with high tumor grade $(p<0.01)$ as $100 \%$ of cases with grade III showed high Ki67 expression. These results were in line with the result of study authored by Yip et al., [18]. However, Madani et al., [19] demonstrated that an insignificant cor- 
relation between histologic grade and Ki-67 expression $(p=0.493)$. Our results revealed also a positive significant statistical correlation between nuclear grade and Ki-67 expression $(p<0.01)$. That result was in agreement with Tashima et al., [20] .

The present study revealed that there was a positive significant statistical correlation between Ki-67 expression and tumor size $(p=0.050)$, lymph node metastasis $(p<0.01)$ and lymphovascular invasion $(p<0.01)$. As $85.7 \%$ of cases with large tumors size $>5 \mathrm{~cm}, 100 \%$ of cases with $(\mathrm{N} 2$ and N3) LN metastasis and 96\% in cases with positive LVI showed high Ki-67 expression. These results were in agreement with Inwald et al., [10]. In against results of study done by Madani et al., [19] was using $20 \%$ as cut off value for Ki-67 evaluation.

The present study revealed that, there was a positive significant statistical correlation between Ki-67 expression and distant metastasis $(p<0.05)$ and tumor stage $(p<0.01)$. This is in parallel with the study of Yuan et al., [21] but In contrast to results of work by Soliman et al., [22] which was done on different histologic types of breast cancer (IDC, ILC and mucinous carcinoma). Also we found a positive significant statistical correlation between Ki-67 expression and NPI $(p<0.01)$. This result agrees with Kurshumliu et al., [23] .

The present results concerning Ki67 may be explained by that activation of Ki-67 leads to ribosomal RNA synthesis and enhance proliferation of tumor cells [24]. Ki-67 directly affects the cell cycle during proliferation phase and could interact with p53, p21, and p27 tumor suppressor genes and modulates cell cycle by affecting the checkpoint of G1 phase [25].

The current study revealed an inverse significant statistically correlation between Ki-67 and ER/PR status as $90.5 \%$ of cases with negative ER and PR receptors showed high Ki-67 expression. This was in agreement with Kontzoglou et al., [17] and Nishimura et al., [26]. This may be explained by that estrogen is a modulator of cellular growth and differentiation. Estrogen mediates most of its functions through two specific intracellular receptors (ERa and ER $\beta$ ) [27].

The Study of Jensen et al., [28] on ERa and ER $\beta$ in breast neoplasms found that the presence of ERa in breast cancer epithelium was associated with a decreased expression of the proliferation markers (Ki-67 and cyclin A), whereas ER $\beta$ expression was associated with elevated levels of these markers.
The present study revealed a positive significant statistical correlation between $\mathrm{Ki}-67$ expression index and Her2 status $(p<0.01)$. This agreed with the studies of Yip et al., [18], Colozza et al., [29] and Nishimura et al., [30].

The current study revealed that, there was a significant statistical correlation between Ki-67 expression index and molecular subtypes $(p<0.01)$ and molecular subtyping can be based on extent of Ki-67 index. These results were in agreement with Wang et al., [12].

The present study revealed a significant statistical correlation between molecular subtypes of cases and age $(p<0.01)$ as $80 \% \& 79 \%$ of luminal $\mathrm{A}$ and $\mathrm{B}$ tumors respectively were occurred in age more than 50 years old, unlike $70 \% \& 73 \%$ of Her2 enriched and Triple negative cases occurred with young age ( $<50$ years old). That result was in line with Liedtke et al., [31]

The present study revealed a positive significant statistical correlation between molecular subtypes and tumor grade $(p<0.01)$ and nuclear grade $(p<$ $0.01)$, tumor size $(p<0.01)$, lymphovascular invasion $(p<0.01)$ and lymph node metastasis $(p$ $<0.01)$, and distant metastasis $(p<0.05) \&$ stage $(p$-value $<0.01)$, NPI $(p<0.01)$ All these results were in parallel to results of study done by Kumar et al., [32].

Claudin-1 is a tight junction protein which maintains cellular polarity and plays a major role in cell-cell communication and epithelial cell homeostasis. Long considered to be a putative tumor suppressor in human breast cancer, new studies suggest a role much more complex [33].

The current study demonstrated a positive significant statistical correlation between claudin-1 expression and all of tumor grade $(p<0.01)$, nuclear grade $(p<0.01)$, tumor size $(p<0.01)$, lymphovascular invasion $(p<0.01)$, lymph node metastasis $(p<0.01)$, distant metastasis $(p<0.01)$, stage $(p<$ $0.01) \&$ NPI $(p<0.01)$. These results were in agreement with the results declared by Ko et al., [34] who demonstrated that CLDN high tumors $(1,3 \&$ 4) are associated with poor prognostic features.

Claudin-1 role in breast cancer may be explained by its role in Epithelial Mesenchymal Transition (EMT). Claudin-1 has the ability to directly promote (EMT) through its interaction with defined EMT-related transcription factors and signaling pathways [35]. In Breast Cancer, claudin1 also increased cell motility and invasiveness 
through its deregulation of MMPs in the extracellular matrix [36]

The present study revealed a negative significant statistical correlation between claudin-1 expression and hormonal receptor expression (ER \& PR) status $(p<0.01)$ as $90.5 \%$ of cases with negative ER \& PR receptors showed high claudin-1 expression while $79 \%$ of cases with positive ER \& PR showed low claudin-1 expression. These findings are in agreement with Blanchard et al., [37] and $\mathrm{Lu}$ et al., [38].

There have been many hypotheses about the mechanisms responsible for the loss of claudin-1 in ER + breast carcinoma. Some studies have shown that epigenetic factors, in particular transcriptional repression, by Claudin-1 promoter methylation near the $\mathrm{CpG}$ islands may be partly responsible for the down regulation of Claudin-1 in ER + tumor tumors [39]

A statistically significant correlation was approved in this work between claudin-1 expression and molecular subtypes $(p<0.01)$. High expression of Claudin-1 was shown in 39\% of cases of luminal B, $90 \%$ of cases of Her2 Enriched and $91 \%$ of cases of triple negative while low expression of claudin-1 was seen in all cases of luminal A, 61\% of cases of luminal B. This result was in line with results published by Lu et al., [38]

The present study revealed that, there was a significant statistical positive correlation between claudin-1 expression and $\mathrm{Ki}-67$ expression in different molecular subtypes of invasive breast carcinoma of NST $(p<0.01)$. This result may be explained by that claudin- 1 high tumors are usually associated with ER negative tumors which usually have poor prognostic features and high proliferation rate as in agreement with Ko et al., [34] and Kolokytha et al., [40].

The study revealed that, by using ROC curve, there was a significant correlation between Ki-67 expression \& Claudin-1 expression and different molecular subtypes. We also found that claudin1 is more sensitive while $\mathrm{Ki}-67$ is more specific in diagnosis of molecular subtypes of invasive carcinoma NS T.

\section{Conclusions:}

Claudin-1 overexpression is associated with aggressiveness and poor prognostic factors in breast ductal carcinoma. Claudin-1 overexpression is correlated with high Ki67 proliferative index. Claudin-1 and Ki-67 may have diagnostic role in discrimination between different molecular sub- types of breast ductal carcinoma. Triple negative tumors \& Her2 enriched tumors may be considerclaudin-1 in1 high tumors.

\section{Conflict of interest:}

No conflict of interest.

\section{References}

1- ZHOU1 B., BLANCHARD A., WANG N., MA X., HAN J., SCHROEDTER I., LEYGUE E., et al.: Claudin-1 promotes migration and increases sensitivity to tamoxifen and anticancer drugs in luminal-like human breast cancer cells MCF7. Cancer Investig., 33: 429-3 9, 2015.

2- EL-BOLKAINY M.N.: Breast cancer. In: El-Bolkainy M. N.: Pathology of cancer. $4^{\text {th }}$ edition, NCI (Cairo), Ch., 18: p. 298-312, 2013.

3- GOLDHIRSCH A., WINER E.P., COATES A.S. and GELBER R.D.: Personalizing the treatment of women with early breast cancer: Highlights of the St. Gallen International Expert Consensus on the Primary Therapy of Early Breast Cancer 2. Annals of Oncology, 24 (9): 2206-23, 2013.

4- SUH Y., YOON C.H., KIM R.K., LIM E.J., OH Y.S., HWANG S.G., et al.: Claudin-1 induces epithelialmesenchymal transition through activation of the c-AblERK signaling pathway in human liver cells. Oncogene, 32: 4873-82, 2013.

5- ANDERSON J.M. and VAN ITALLIE C.M.: Physiology and Function of the Tight Junction. Cold Spring Harbor Perspectives in Biology, 1 (2): a002584, 2009.

6- ZHOU B., MOODIE A., BLANCHARD A.A.A., LEYGUE E. and MYAL Y.: Claudin 1 in Breast Cancer: New Insights. Grant-Kels J., ed. Journal of Clinical Medicine, 4 (12): 1960-76, 2015.

7- LEECH A.O., CRUZ RG.B., HILL A.D.K. and HOPKINS A.M.: Paradigms lost-an emerging role for over-expression of tight junction adhesion proteins in cancer pathogenesis. Annals of Translational. Medicine, 3 (13): 184, 2015.

8- KWON M.J.: Emerging Roles of Claudins in Human Cancer. International Journal of Molecular Sciences 14 (9): 18148-80, 2013.

9- LU S., SINGH K., MANGRAY S., TAVARES R., NOBLE L., RESNICK M.B. and YAKIREVICH E.: Claudin Expression in High Grade Invasive Ductal Carcinoma of the Breast: Correlation with the Molecular Subtype. Modern pathology: An official journal of the United States and Canadian Academy of Pathology, Inc., 26 (4): 485-95, 2013.

10- INWALD E.C., KLINKHAMMER-SCHALKE M., HOFSTÄDTER F., ZEMAN F., KOLLER M., GERSTENHAUER M. and ORTMANN O.: Ki-67 is a prognostic parameter in breast cancer patients: Results of a large population-based cohort of a cancer registry. Breast Cancer Research and Treatment, 139 (2): 539-52, 2013.

11- INIC Z., ZEGARAC M., INIC M., MARKOVIC I., KOZOMARA Z., DJURISIC I. and JANCIC S.: Difference between Luminal A and Luminal B Subtypes According to Ki-67, Tumor Size, and Progesterone Receptor Negativity Providing Prognostic Information. Clinical Medicine Insights Oncology, 8: 107-11, 2014. 
12- WANG J., SANG D., XU B., YUAN P., MA F., LUO Y. and LI Q.: Value of Breast Cancer Molecular Subtypes and Ki67 Expression for the Prediction of Efficacy and Prognosis of Neoadjuvant Chemotherapy in a Chinese Population. Zhou. W., ed. Medicine, 95 (18): e3518, 2016.

13-PAYANDEH M., SADEGHI M., SADEGHI E. and AEINFAR M.: Clinicopathology figures and long-term effects of tamoxifen plus radiation on survival of women with invasive ductal carcinoma and triple negative breast cancer. Asian. Pac. J. Cancer. Prev., 16: 4863-7, 2015.

14- Egyptian National Cancer Insistitute (NCI), Pathology Cancer Registry, 2013.

15- HENG Y.J., LESTER S.C., TSE G.M., FACTOR R.E., ALLISON K.H., COLLINS L.C. and BECK A.H.: The molecular basis of breast cancer pathological phenotypes. J. Pathol., 241: 375-91, 2017.

16- HEARNE B.J., TEARE D., BUTT M. and DONALDSON L.: Comparison of Nottingham Prognostic Index and Adjuvant Online prognostic tools in young women with breast cancer: Review of a single-institution experience. BMJ. Open, 5: e005576, 2017.

17- KONTZOGLOU K., PALLA V., KARAOLANIS G., ALEXIOU I., PATERAS I., KONSTANTOUDAKIS K., et al.: Correlation between $\mathrm{Ki} 67$ and breast cancer prognosis. Oncology, 84: 219-25, 2013.

18- YIP C.H., BHOO-PATHY N., DANIEL J.M., FOO Y., MOHAMED A., ABDULLAH M., NG Y., et al.: Roles of Ki67 in Breast Cancer-Important for Management? APJCP, 17 (3): 1077, 2016.

19- MADANI S., PAYANDEH M., SADEGHI M., MOTAMED H. and SADEGHI E.: The correlation between Ki-67 with other prognostic factors in breast cancer: A study in Iranian patients. Indian J. Med. Paediatr. Oncol., 37: 95, 2016.

20- TASHIMA R., NISHIMURA R., OSAKO T., NISHIYAMAY., OKUMURA Y., NAKANO M. and ARIMA N.: Evaluation of an Optimal Cut-Off Point for the Ki-67 Index as a Prognostic Factor in Primary Breast Cancer: A Retrospective Study. PLoS ONE, 10 (7): e0119565, 2015.

21- YUAN P., XU B., WANG C., ZHANG C., SUN M. and YUAN L.: Ki 67 expression in luminal type breast cancer and its association with the clinicopathology of the cancer. Oncology Letters, 11: 2101-5, 2016.

22- SOLIMAN N.A. and YUSSIF S.M.: Ki-67 as a prognostic marker according to breast cancer molecular subtype. Cancer Biol. Med., 13 (4): 496-504, 2016.

23- KURSHUMLIU F., GASHI-LUCI L., KADARE S., ALIMEHMETI M. and GOZALAN U.: Classification of patients with breast cancer according to Nottingham Prognostic Index highlights significant differences in immunohistochemical marker expression. World Journal of Surgical. Oncology, 12: 243, 2014.

24- BULLWINKEL J., BARON-LÜHR B., LÜDEMANN A., WOHLENBERG C., GERDES J. and SCHOLZEN T.: "Ki-67 protein is associated with ribosomal RNA transcription in quiescent and proliferating cells". J. Cell Physiol., (3): 624-35, 2006.

25- RAHMANZADEH R., HÜTTMANN G., GERDES J. and SCHOLZEN T.: Chromophore-assisted light inactivation of pKi-67 leads to inhibition of ribosomal RNA synthesis. Cell Prolif, 40 (3): 422-30, 2007.

26- NISHIMURA R., OSAKO T., NISHIYAMA Y., TASHIMA R. and NAKANO M., FUJISUE M. and ARIMA N.: Prognostic significance of $\mathrm{Ki}-67$ index value at the primary breast tumor in recurrent breast cancer. Molecular and Clinical Oncology, 2 (6): 1062-8, 2014.

27- WARNER M., NILSSON S. and GUSTAFSSON J.A.: The estrogen receptor family Curr. Opin. Obstet. Gynecol., 11: 249-54, 1999.

28- JENSEN E.V., CHENG G., PALMIERI C., SAJI S., MÄKELÄ S., VAN NOORDEN S. and GUSTAFSSON J. AKE.: Estrogen receptors and proliferation markers in primary and recurrent breast cancer. PNAS, 98 (26): 15197-202, 2001.

29- COLOZZA M., AZAMBUJA E., CARDOSO F., SOTIRIOU C., LARSIMONT D. and PICCART M.J.: Proliferative markers as prognostic and predictive tools in early breast cancer: Where are we now? Ann. Oncol., 16: 172339, 2005.

30- NISHIMURA R., OSAKO T., OKUMURA Y., HAYASHI M., TOYOZUMI Y. and ARIMA N.: Ki-67 as a prognostic marker according to breast cancer subtype and a predictor of recurrence time in primary breast cancer. Exp. Ther. Med., 1: 747-54, 2010 .

31- LIEDTKE C., RODY A., GLUZ O., BAUMANN K., BEYER D., KOHLS E.B., LAUSEN K., et al.: The prognostic impact of age in different molecular subtypesof breast cancer. Breast. Cancer Res. Treat., 152: 667-73, 2015.

32- KUMAR B.N., PATNI L.C.P., AGARWAL C., KHAN M.A. and PARASHAR N.: Prevalence of molecular subtypes of invasive breast cancer: A retrospective study. Medical Journal Armed Forces India, 71: 254e258, 2015.

33- ZHOU1 B., BLANCHARD A., WANG N., MA X., HAN J., SCHROEDTER I., LEYGUE E., et al.: Claudin-1 promotes migration and increases sensitivity to tamoxifen and anticancer drugs in luminal-like human breast cancer cells MCF7. Cancer Investig., 33: 429-39, 2015.

34- KO B.S., KIM H.J., YU J.H., LEE J.W., SOHN B.H., KIM S.B., GONG G., et al.: Claudin-1 1, 3, 4, and 7 expression in triple-negative breast cancer. J. Clin. Oncol., 3131, 2013.

35- MARTINEZ-ESTRADA O.M., CULLERES A., SORIANO F.X., PEINADO H., BOLÓS V., MARTÍNEZ F.O. and VILARÓ S.: The transcription factors slug and snail act as repressors of claudin-1 expression in epithelial cells. Biochemical Journal, 394 (Pt 2): 449-57, 2006.

36- MIYAMORI H., TAKINO T., KOBAYASHI Y., TOKAI H., ITOH Y., SEIKI M. and SATO H.: Claudin promotes activation of promatrix metalloproteinase-2 mediated by membrane-type matrix metalloproteinases. J. Biol. Chem., 276: 28204-11, 2012.

37- BLANCHARD A.A., SKLIRIS G.P., WATSON P.H., MURPHY L.C., PENNER C., TOMES L., YOUNG T.L., et al.: Claudins 1, 3, and 4 protein expression in ER negative breast cancer correlates with markers of the basal phenotype," Virchows Archiv., 454 (6): 647-56, 2009. 
38- LU S., SINGH K., MANGRAY S., TAVARES R., NOBLE L., RESNICK M.B. and YAKIREVICH E.: Claudin expression in high-grade invasive ductal carcinoma of the breast: Correlation with the molecular subtype. Mod. Pathol., 26: 485-95, 2013.

39- Di CELLO F., COPE L., LI H., JESCHKE J., WANG W., BAYLIN S.B. and ZAHNOW C.A.: Methylation of the claudin-1 promoter is associated with loss of expression in estrogen receptor positive breast cancer. PLoS One, 8: 63-8, 2013.

40- KOLOKYTHA P., YIANNOU P., KERAMOPOULOS D., KOLOKYTHAS A., NONNI A., PATSOURIS E. and PAVLAKIS K.: Claudin-3 and claudin-4: Distinct prognostic significance in triple-negative and luminal breast cancer. Appl. Immunohistochem. Mol. Morphol., 22 (2): 125-31, 2014

\section{تقييم الدالة المناعية (Claudin-1) والدالة المناعية (Ki-67)

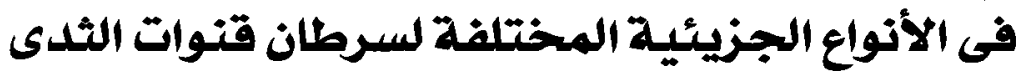 (دراسة مناعية)}

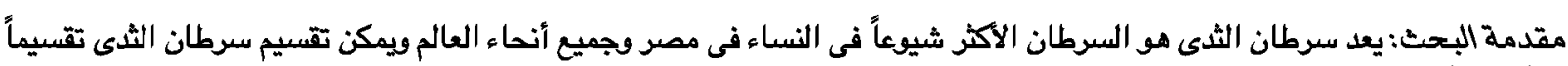

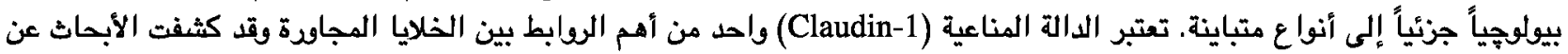

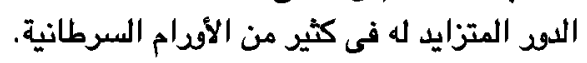

طرية الدراسة: قد قام هذا البحث على دراسة عه حالة مصابة بسرطان قنوات الثى وذلك لدراسة مستوى كل من (Claudin-1) و (67-

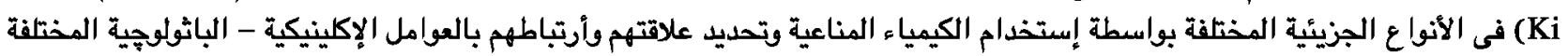
في سرطان قنوات الثدى.

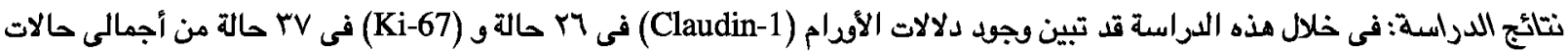

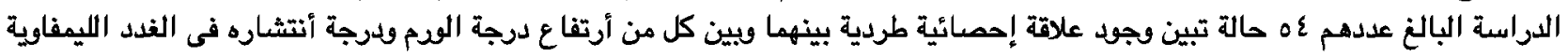

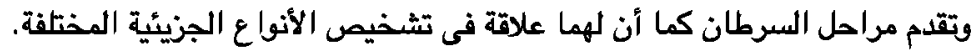

ومن ثم يمكن أستتاج: أن دلالات الأودام (Claudin-1) و (Ki-67) قد يكن لهما دواً رئيسياً في تطود وتقدم سرطان قنواتالثدى وأيضاً قد يكن لهما دوراً تشخيصاً فى التقرقة بين الأنواع الجزيئة المختلفة لسرطان الهان الثدى. 